\title{
THE ELASTIC BUCKLING BEHAVIOR OF (5056-H18)AL- ALLOY COLUMNS UNDER VARIABLE LOAD
}

\author{
Ali Yousuf Khenyab \\ Hussein FadhilAjaj \\ Rawa Ahmed Helal \\ al2024t4@gmail.com__Husseinfadhil358@gmail.com__rawahelal@yahoo.com \\ Electromechanical Engineering Department, University of Technology
}

\begin{abstract}
The research deals the evaluation of buckling behavior for 5056-H18 Al alloy columns under variable loads and studies the effect of initial deflection on the critical buckling load. Seven samples were used for the purpose of testing the buckling of the column. The critical deflection of the column can be determined by measuring a length multiplied by 0.01 and this is the critical load of the columns. For the purpose of measuring the critical deviation of the column, a digital dial gauge has been applied and it set at 0.7 distance from the length of the column from the fixed condition. The experimental results were compared with the Perry - Robertson formula, Euler's theory for long columns and with the values calculated from the ANSYS 17 program. It has been observed that the Euler formula showed good compatibility with the practical results with safety factor 1.5. The ANSYS results showed well agreement taking a 1.5 factor of safety. While the Perry-Robertson formula needs a 1.4 safety factor to be safe results compared with experimental results.
\end{abstract}

Keywords: elastic buckling, ansys17, perry-robertson formula, (5056-h18) al-alloy, lateral deflection

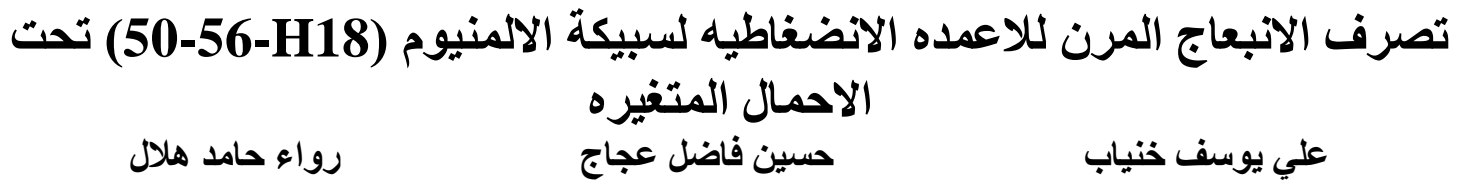

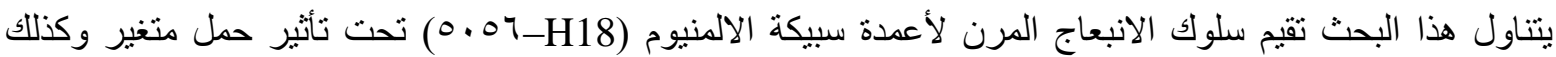

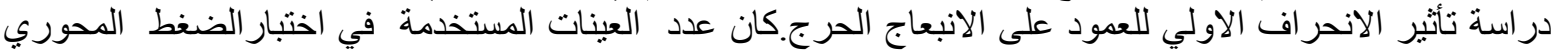

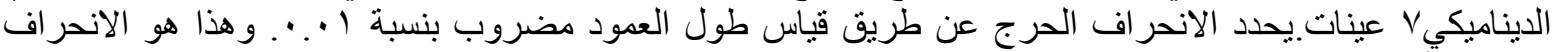

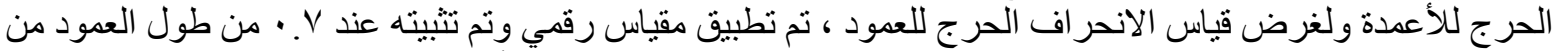

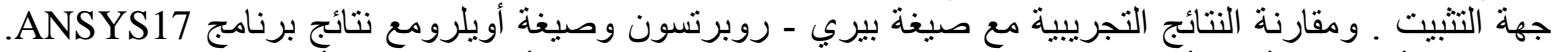

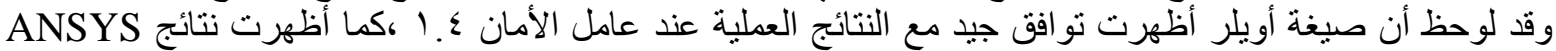

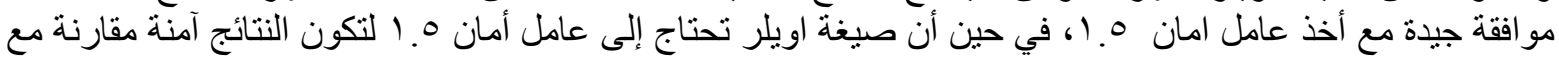
النتائج التجريبية. 


\section{INTRODUCTION}

There are a number of limit states, or conditions for which a structure can be deemed unusable and can be considered to have failed. Structures can fail when members or the entire structure reach yield or ultimate strength, exceed a specified maximum deflection, or when a fracture of members or collapse occurs. Buckling of members, not commonly considered to be a separate limit state, presents a stability issue that resembles a limit state in that it limits the resistance that can be developed by the member [Charles, 2003]. Calculating the stability of structures has always been an important engineering discipline. Especially the calculation of the critical buckling load of a structure had been a subject for study since Leonard Euler in 1744 who calculated the critical buckling load for a simply supported column [Allan and Kasper, 2012]. Buckling is kind of failures that lead to an unexpected collapse in frames when the column has been subject to pivotal load. When a column of a frame has been loaded with a little axial compression stress, it has been deformed with a remarkable variation in geometry. At the point of high load value, the frame unexpectedly experiences a big deformed and may forfeit its constancy to carry the load [Rekhaand, Kalurkar, 2014]. A column is a structural member that carries an axial compressive load and that tends to fail by elastic instability or buckling. Column slenderness influences greatly a column's ability to carry the load. Due to a column has been a compression member, it would be reasonable to assume that one would fail because pulverize or immoderate dereliction once the stress level exceeded the yield point. For generality columns, the failure happens at a lower grade than the column's strength due to them is comparatively slender (long to the lateral dimension) and washout because of the buckling. Buckling has been the surprising uncontrolled longitudinal displacement of a column, at maximum load can be supported. The elastic instability has been the state of failure in which the form of the column has been insufficiently rigid to hold it upright under load. At buckling point, a radial deflection of the axis of the column happens suddenly, and the column will collapse if the load is not reduced [Hussein, 2010]. The buckling of the beams under combined loading of the pivotal and side bending loads with three pivotal load application arrangements for the same beam was studied by Amir et al, the experimental results of the critical buckling load gained experimentally had been compared with FEM, and both methods are agreed upon [Amir and Zodiac, 2012]. H.X.Yuan, et al [6] (2015), studied the thump column of alloys 6061T6 and 6063-T5 and examined under axial compression between two fixed end supports. The critical local buckling strengths have been specified from the measured out-of-level deflections and surface strains corresponding to the plate elements, which has been moreover compared with the theoretical and analytical results taking into account element interaction and material nonlinearity. It has been detected that the foretell compressive strengths from the four design standards were mostly conservative, especially for the cross-sections made of aluminum alloys with pronounced strain hardening properties. Columns of aluminum alloy had been studied by MeiLiu, et al, and numerically to investigate the buckling behavior and to assess the reliability of present design methods. A result of the tensile test had been compared with those foretell by the present American, European and Chinese description of aluminum alloy structures and the Direct Strength Method (DSM) on thin-walled frames. After reliability analysis, the design strength estimate by current design description has been found to be generally conservative, but DSM gave more accurate results [Mei et al, 2015].

Yicun Chang, et al [8](2016), Buckling was studied behaviors and ultimate strength of aluminum alloy columns with a misshapen cross-section. The local buckling and distortion buckling have been discovered by the turning points on the load-axial plucking out curves. The out-of-plane displacement along the column length at failure has been used to explain the failure process of the column. Ultimate strengths and failure processes of 174 columns failed by interacted buckling failure modes have been investigated. 
5056-H18 aluminum is 5056 aluminum in the H18 temper. This is the strongest temper normally produced through the action of only strain hardening. Good corrosion resistance to sea water which could be the controlling factor in structural design under some special circumstances, good finish when buffed or anodized. Marine parts, bus and truck bodies

The present work deals with testing column bulking under axial compressive load for pinnedfixed ends condition. The experimental results compared to the results obtained from PerryRobertson formula, Euler formula and ANSYS version (17) to evaluate the critical buckling using (5065-H18) Al-alloy column.

\section{THEORETICAL INVESTIGATION}

\section{Euler formula}

The buckling behavior of slender columns within their elastic limits first was investigated by a Swiss mathematician Leonhard Euler (1707-1783). Euler's equation presents the relationship between the load that causes buckling of a pinned end column and the lateral deflection. In this research, the Euler formula was derived for a specimen that is fixed-pined state shown in figure (1). The critical buckling load can be determined by the equation:

$$
P_{c r}=\frac{2.046 \pi^{2} \mathrm{EI}}{L^{2}}[\text { Gere, } 2009]
$$

Where

$\mathrm{E}=$ Modulus of elasticity $(\mathrm{GPa})$

$\mathrm{I}=$ Moment of inertia $\left(\mathrm{mm}^{4}\right)$

$\mathrm{L}=$ length of column ( $\mathrm{mm})$

\section{Perry-Robertson theory}

It is designed to avoid the defects of the Euler formula for long columns. The formula of PerryRobertson depends on the mechanical properties of the material and also on the dimensions of the column. In this formula, the initial deflection of the column was taken into consideration [Hearn, 1997]. Total buckling at any point is specified by:

$p_{c r}=A\left[\frac{\sigma_{y}+(1+\eta) \sigma_{e}}{2}-\frac{1}{4} \sqrt{\left(\sigma_{y}+(1+\eta) \sigma_{e}\right)^{2}-2 \sigma_{y} \sigma_{e}}\right]$

Where

$\sigma_{e}=$ Euler stress $(\mathrm{MPa})$

$\sigma_{y}=$ Yield stress $(\mathrm{MPa})$

$\eta=0.015(\mathrm{~L} / \mathrm{r})$ for a brittle material

$\eta=0.3\left(\frac{L_{E}}{100 r}\right)^{2}$ For a ductile material

$\mathrm{r}=\sqrt{\frac{\mathrm{I}}{A}}(4)$

$\sigma_{e}=\frac{\pi^{2} E}{\left(L_{e} / r\right)^{2}}$

$\mathrm{Le}=\mathrm{KL}$

$\mathrm{K}=$ end fixed constant as shown in Figure(2).

The columns are classified into long, intermediate and short and this classification depends on the two formulas, the slenderness ratio (S.R) and the column constant (Cc). 


$$
\begin{aligned}
& \mathrm{S} . \mathrm{r}=\frac{L e}{r}=\frac{k L}{r} \\
& \mathrm{Cc}=\sqrt{\frac{2 \pi^{2} E}{\sigma_{y}}}
\end{aligned}
$$

The column constant depends on the mechanical properties of the column. If the slenderness ratio (S.R.) for a column is less than the column constant ( $\mathrm{Cc}$ ) then the column is intermediate. If the slenderness ratio (S.R) is more than the column constant the column is long. In this research, the experimental examination of the fixed-pinned case will be adopted see figure (2-C) [Fadhel, 2014].

\section{Failure Definition}

$1 \%$ of the sample length is the permissible side deflection. When the side deflection of the sample reaches this ratio and does not override it lead to the critical buckling of the columns. When the deflection of column override this ratio $(1 \% \mathrm{~L})$, the specimen fails [Hussein, 2010].After the test specimen is installed in the test-rig and locate digital dial gauge indicator at the 0.7 distance from the effective length from the fixed end, where read and record initial deflection.

\section{EXPERIMENTAL PROCEDURE}

\section{Chemical Compositions}

Table (1) shows the chemical composition analysis obtained from Company State for Engineering Rehabilitation and Inspection (SIER).

\section{Mechanical Properties}

The mechanical properties were completed using the (W D W - $200 \mathrm{E}$ ) tensile testing machine with an energy of $200000 \mathrm{~N}$. The tensile testing of (5056-H18 aluminum alloy) was found according to ASTM A370 specification. The experimental results are the average of three samples as shown in table (2).

\section{Buckling Specimens}

The samples used in the current research are made of 5056-H18 aluminum alloy with $400 \mathrm{~mm}$ in length and $10 \mathrm{~mm}$ in diameter as shown in Figure (4). The dimensions of the Sample are shown in Table (4).

\section{Buckling Tests - Rig}

The buckling test-rig machine has shown in Figure (4) which used in this work. The Test-Rig machine consists of the following parts:-

1- Torsion system.

2- Compression system.

(The buckling machine is located in the strength laboratory in the Department of Electromechanical Engineering at the University of Technology).The column ends supports of fixed-pinned with rotating speed of $17 \mathrm{rpm}$ were adopted. 


\section{Torsion System :}

The torsion system consists of an electrical motor of $(0.5 \mathrm{KW})$, operating at two different speeds, low speed (17 r.p.m) and high-speed (34 r.p.m) and when the electrical motor starts, it causes movement in two different directions clockwise and counterclockwise. A cycle-counter indicator (indicates the number of cycles), is fixed in the front of the control panel. The register digits are (99999.9), it refers to the number of cycles during the test. Figure (4) shows the torsion system of the test-rig machine.

\section{Compression System:}

The system of compression includes the manual hydraulic pump connecting with an analog gauge of maximum pressure up to $(315$ bar $)$. It uses the shaft screw to transfer pressure from the pump in the jaw that supports the sample.

\section{RESULTS AND DISCUSSION}

\section{The Buckling of the Column During Rotation}

Seven samples were tested under variable compression dynamic loading. The test-rig has two speeds $17 \mathrm{rpmand} 34 \mathrm{rpm}$. The lowest speed is $17 \mathrm{rpm}$ has been used because it is difficult to detect the buckling phenomenon at high speed. It is also difficult to control the sample at high speed. The samples were tested with one slenderness ratio, for testing under increasing loads. Table (4) shows the date for the samples tested under increasing loads for long columns (5056H18). From table (4) it was noted initial deflection of a column has an important effect on compression dynamic critical buckling load. When the initial deflection increases, will the critical buckling load decrease as shown in figure(6). These results coincide with what was finding by ref [Hussein, 2010. Fadhil, 2014]. When the column is exposed to axial load at the pinned end, it starts to buckle gradually and increases the lateral deflection by increasing the load. the critical buckling of a long column called elastic buckling.

\section{Application of Perry- Robertson formula, Euler formula and ANSYS 17}

When using the Perry-Robertson formula and comparing it with the experimental results can be observed satisfactory results, but when taking safety factor 1.4, the results become very accurate, this will allow the column with high safety estimation for Pcr under dynamic compressive loading. Euler's formula has been used for appreciation of critical buckling load, and it can be beneficial to evaluate the buckling in the early stages of the design process. Euler's equation is valid for the long column. Form Table (5), The Euler equation for the long columns gives inaccurate date compared with the practical date for the critical buckling of the column but with a safety factor of (1.5), it is giving accurate results. ANSYS17 (APDL) package was used and its data had been compared with the results from the test-rig. Table (5) show the Finite Element Method (FEM) result of the Pcr under increasing compressive load without the use of a factor of safety (F.S) but with a (1.5) factor of safety showed good agreement in comparison with the analytical and experimental results. These deflection of the long column as shownin Figure (8). The differences that can be observe between the values calculated by the ANSYS package17 program and the values obtained empirically are due to the difficulties of control and measurement in the ANSYS program and some errors resulting from the measurement of experimental data.

\section{CONCLUSIONS}

The compressive buckling behavior of 5056-H18 aluminum alloy columns with fixed-pinned end conditions has been experimentally and numerically investigated in this study. 
1-It has noted initial deflection of a column is an important effect on compression dynamic critical buckling load. When the initial deflection increases, will the critical buckling load decrease.

2-The Perry -Robertson formulas gives an approximation of the experimental results but with a safety factor of (1.4) that gives more satisfied expectations.

3- The Euler equation for the long columns and Jenson for the short and intermediate columns give unsatisfying results compared with the experimental results for the critical buckling but with a safety factor of (1.5) it is giving accurate results.

4. A numerical model using ANSYS package was employed. A factor of safety (1.5) showed good agreement in comparison with the analytical and experimental results.

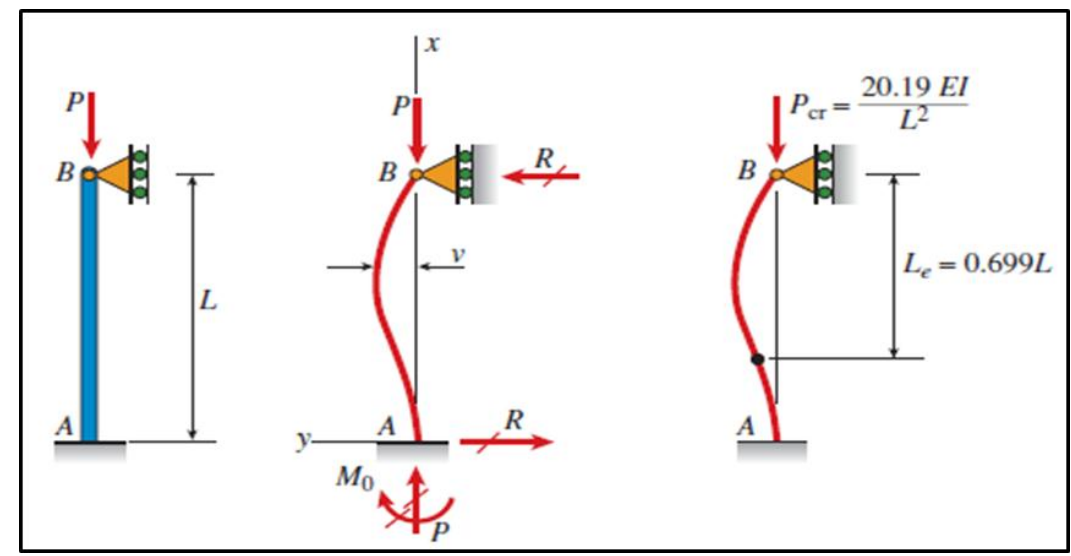

Figure (1): fixed-pined column conditions [10].

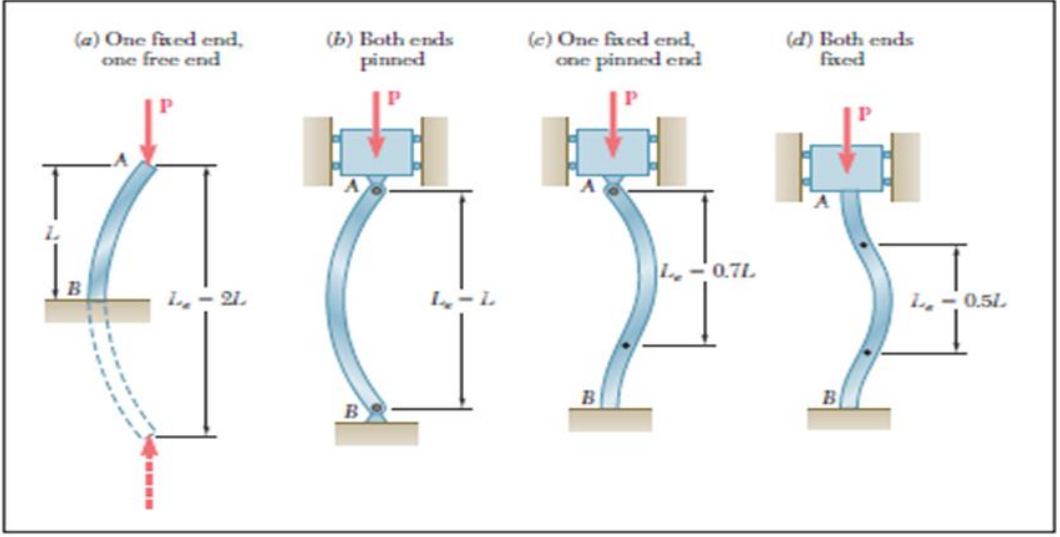

Figure (2): kinds of columns fixity [Fadhel, 2014]

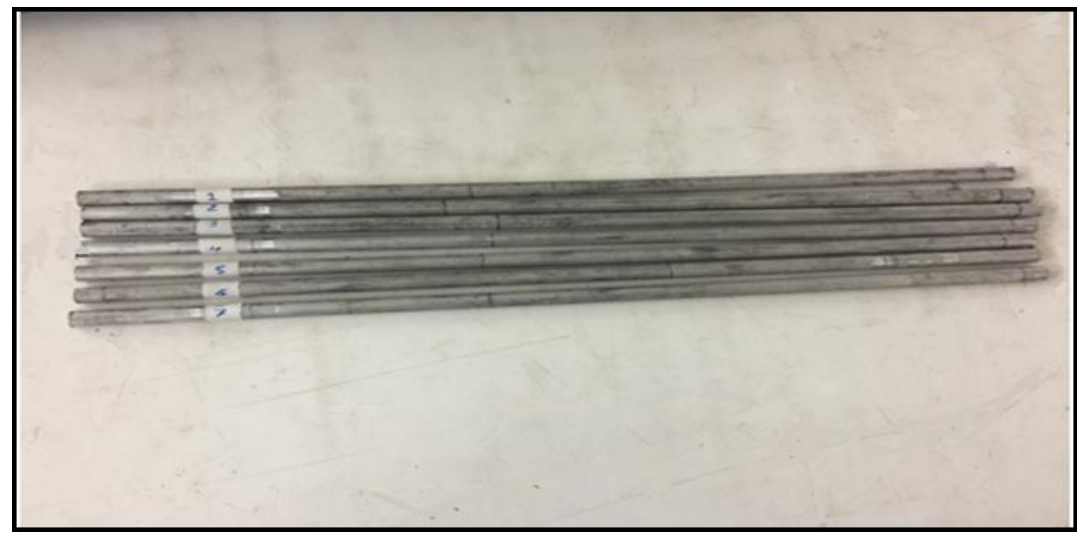


Figure (3): buckling specimens for long columns.

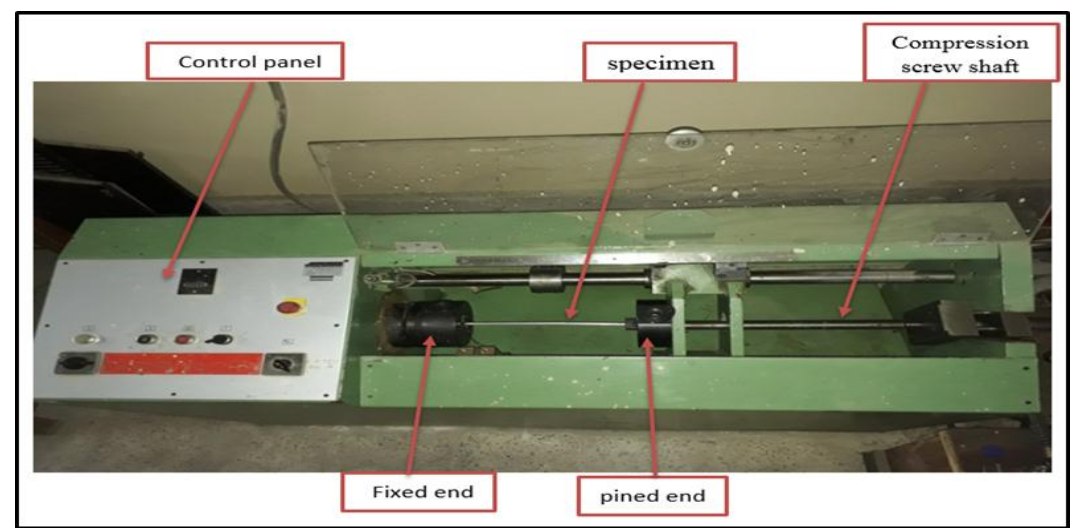

Figure (4): machine of buckling test-rig used in this work.

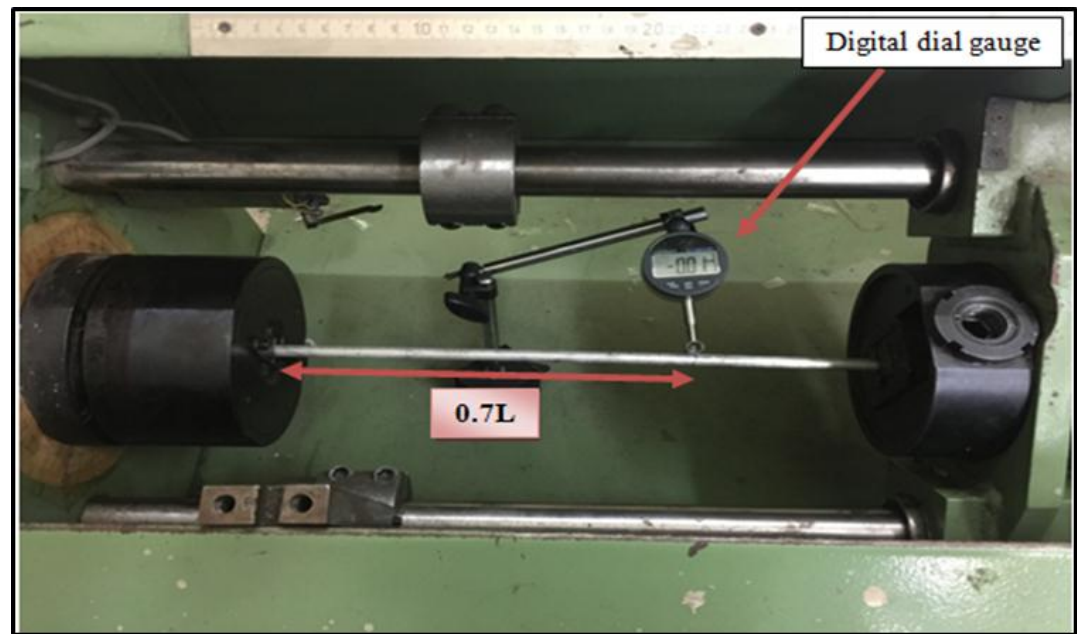

Figure (5): digital dial gauge with buckling specimen during the test

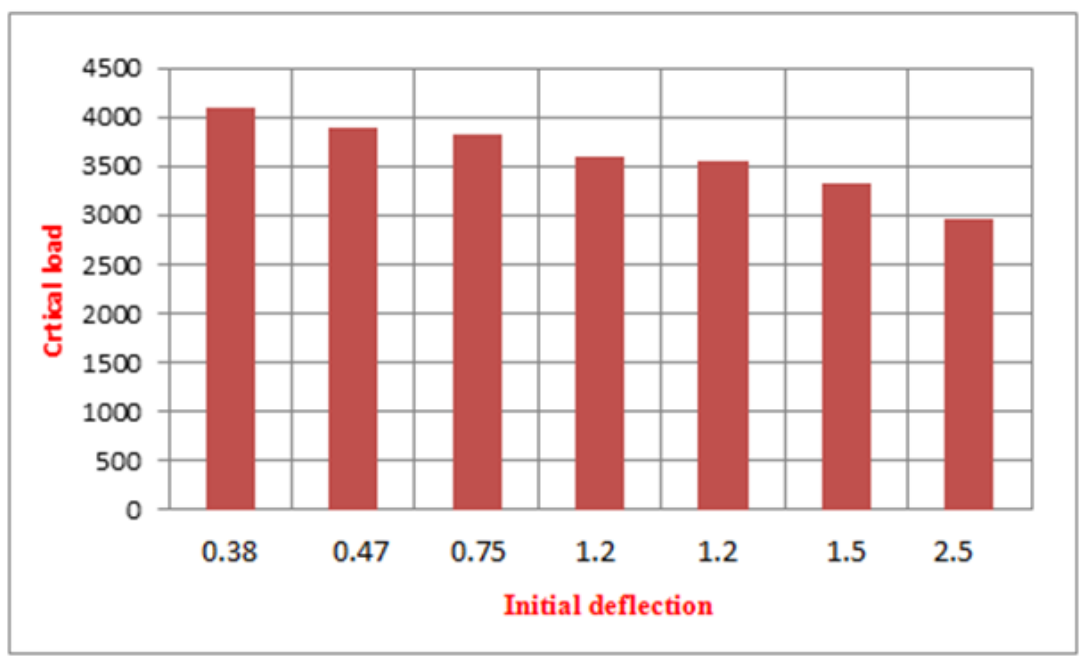

Figure (6): the relationship between critical load and initial deflection 


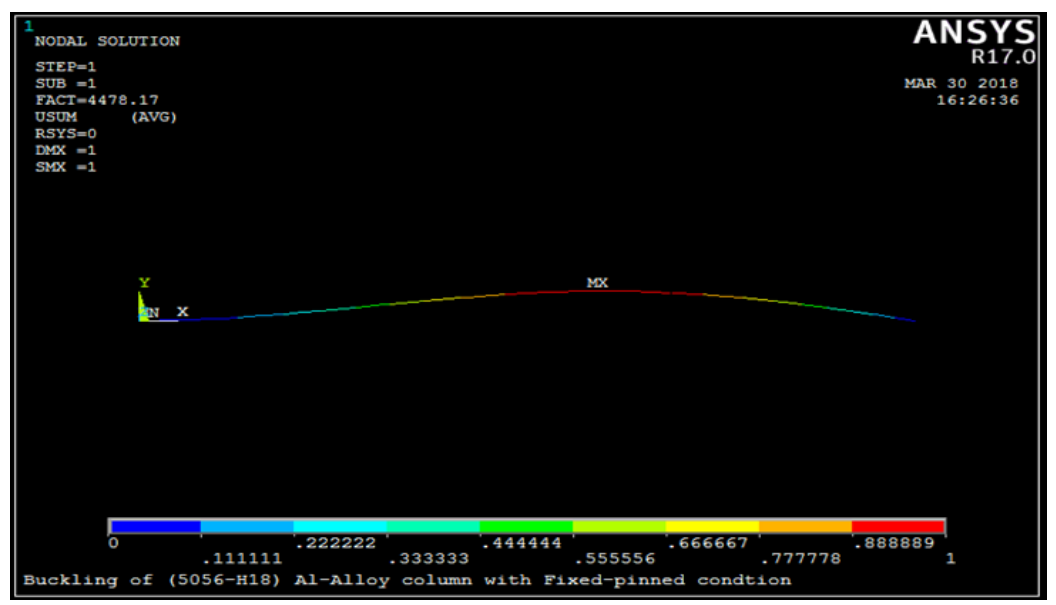

Figure (7): the deflection shape for lateral buckling for the long column as shown

Table (1): shows the chemical composition analysis obtained for 5056-H18 Aluminum alloy.

\begin{tabular}{|c|c|c|c|c|c|c|c|c|c|}
\hline $\begin{array}{c}5056-\mathrm{H} 18 \\
\text { Aluminum alloy }\end{array}$ & Al\% & $\mathrm{Cr} \%$ & $\mathrm{Cu} \%$ & $\mathrm{Fe} \%$ & Mg\% & Mn \% & $\mathrm{Si} \%$ & Ti\% & $\mathrm{Zn \%}$ \\
\hline Standard [12] & 92.9-95.4 & $0.05-0.2$ & $\begin{array}{c}\text { Max } \\
0.10 \\
\%\end{array}$ & $\begin{array}{c}\text { Max } \\
0.40 \\
\%\end{array}$ & $4.5-5.6$ & $\begin{array}{l}\text { 0.05-0.20 } \\
\%\end{array}$ & $\begin{array}{c}\text { Max } \\
\mathbf{0 . 3} \\
\%\end{array}$ & $\begin{array}{l}\text { Max } \\
0.15\end{array}$ & $\begin{array}{l}\text { Max } \\
0.10\end{array}$ \\
\hline Experimental & Balance & 0.0572 & 0.12 & 0.45 & 3.17 & 0.176 & 0.39 & 0.137 & 0.12 \\
\hline
\end{tabular}

Table (2): The mechanical properties of (5056-H18aluminum alloy)

\begin{tabular}{|c|c|c|c|c|c|}
\hline $\begin{array}{c}5056-H 18 \\
\text { Aluminum } \\
\text { Alloy }\end{array}$ & $\begin{array}{c}\sigma_{\mathrm{u}} \\
(\mathrm{MPa})\end{array}$ & $\begin{array}{c}\sigma_{\mathbf{y}} \\
(\mathbf{M P a})\end{array}$ & $\begin{array}{c}\mathbf{E} \\
(\mathbf{G P a})\end{array}$ & $\begin{array}{c}\mathbf{G} \\
(\mathbf{G P a})\end{array}$ & $\begin{array}{c}\text { Poi. Ratio } \\
(\mathbf{v})\end{array}$ \\
\hline Standard [12] & 435 & 405 & 71 & 26 & $\mathbf{0 . 3 3}$ \\
\hline Experimental & 419 & 394 & 72 & 27 & $\mathbf{0 . 3 2}$ \\
\hline
\end{tabular}

Table (3): gives the dimensions of solid specimens (seven specimens) used for 5056-H18 aluminum alloy

\begin{tabular}{|c|c|c|c|c|c|c|c|c|}
\hline $\begin{array}{c}\text { L } \\
\mathbf{m m}\end{array}$ & $\begin{array}{c}\text { Le } \\
\mathbf{m m}\end{array}$ & $\begin{array}{c}\text { D } \\
\mathbf{m m}\end{array}$ & $\begin{array}{c}\mathbf{r} \\
\mathbf{m m}\end{array}$ & $\begin{array}{c}\text { I } \\
\mathrm{mm}^{4}\end{array}$ & $\begin{array}{c}\text { A } \\
\mathrm{mm}^{2}\end{array}$ & SR & Cc & $\begin{array}{c}\text { Type of } \\
\text { column }\end{array}$ \\
\hline 400 & $\mathbf{2 8 0}$ & $\mathbf{1 0}$ & 2.5 & 490.87 & 78.53 & 112 & 60 & Long \\
\hline
\end{tabular}


Table (4): the information of the samples tested under increasing compression load (5056-H18)

\begin{tabular}{|c|c|c|c|c|c|c|}
\hline $\begin{array}{l}\text { SP } \\
\text { No. }\end{array}$ & $\begin{array}{c}\mathbf{L} \\
(\mathbf{m m})\end{array}$ & $\begin{array}{c}\text { Le } \\
(\mathbf{m m})\end{array}$ & $\begin{array}{c}\mathbf{D} \\
(\mathbf{m m})\end{array}$ & $\begin{array}{l}\mathbf{P}_{\mathrm{cr}} \\
(\mathbf{N})\end{array}$ & $\begin{array}{c}\boldsymbol{\delta}_{\text {in }} \\
(\mathbf{m m})\end{array}$ & $\begin{array}{c}\boldsymbol{\delta}_{\text {cr }} \\
(\mathbf{m m})\end{array}$ \\
\hline 1 & 400 & 280 & 10 & 3887 & 0.47 & 4.2 \\
\hline 2 & 400 & 280 & 10 & 4099 & 0.38 & 4.1 \\
\hline 3 & 400 & 280 & 10 & 3817 & 0.75 & 4.5 \\
\hline 4 & 400 & 280 & 10 & 3604 & 1.2 & 3.9 \\
\hline 5 & 400 & 280 & 10 & 2968 & 2.5 & 4.2 \\
\hline 6 & 400 & 280 & 10 & 3550 & 1.4 & 3.7 \\
\hline 7 & 400 & 280 & 10 & 3318 & 1.5 & 4.4 \\
\hline
\end{tabular}

Table (5): comparing between Perry-Robertson, Euler, ANSYS 17data with the results that taking from test-rig

\begin{tabular}{|c|c|c|c|c|c|c|c|c|}
\hline $\begin{array}{l}\text { SP } \\
\text { No. }\end{array}$ & $\begin{array}{c}\mathbf{L} \\
(\mathbf{m m})\end{array}$ & $\begin{array}{c}\text { Le } \\
(\mathbf{m m})\end{array}$ & $\underset{(\mathbf{m m})}{\mathrm{D}}$ & $\begin{array}{l}\mathbf{P}_{\mathrm{cr}} \\
(\mathbf{N}) \\
\text { EXP }\end{array}$ & $\begin{array}{c}\mathrm{P}_{\mathrm{cr}} \\
(\mathrm{N}) \\
\text { EXP } \\
\text { Average }\end{array}$ & $\begin{array}{c}\mathrm{P}_{\mathrm{cr}} \\
(\mathrm{N}) \\
\text { Perry- } \\
\text { Robertson }\end{array}$ & $\begin{array}{c}\mathbf{P}_{\mathrm{cr}} \\
(\mathbf{N}) \\
\text { Euler }\end{array}$ & $\begin{array}{c}\mathbf{P}_{\mathrm{cr}} \\
(\mathrm{N}) \\
\text { ANSYS } \\
\text { V17 } \\
\end{array}$ \\
\hline 1 & 400 & 280 & 10 & 3887 & \multirow{6}{*}{3142} & \multirow[t]{2}{*}{4186} & \multirow[t]{2}{*}{4451} & \multirow[t]{2}{*}{4478} \\
\hline 2 & 400 & 280 & 10 & 4099 & & & & \\
\hline 3 & 400 & 280 & 10 & 3817 & & \multirow{3}{*}{$\begin{array}{c}\text { With } \\
\text { S.F of } \\
1.4\end{array}$} & \multirow{3}{*}{$\begin{array}{c}\text { With S.F } \\
\text { of } \\
1.5\end{array}$} & \multirow{3}{*}{$\begin{array}{c}\text { With } \\
\text { S.F of } \\
1.5\end{array}$} \\
\hline 4 & 400 & 280 & 10 & 3604 & & & & \\
\hline \multirow[t]{2}{*}{5} & \multirow[t]{2}{*}{400} & \multirow[t]{2}{*}{280} & \multirow[t]{2}{*}{10} & \multirow[t]{2}{*}{2968} & & & & \\
\hline & & & & & & 2990 & 2967 & 2985 \\
\hline
\end{tabular}

\section{REFERENCES}

a.Charles E. Riley, Elastic Buckling Loads of Slender Columns With Variable Cross Section by the Newmark Method, M.Sc. Thesis, Colorado State University, 2003.

b.Allan L. F., Kasper S. L., Methods for Decreasing the Total Solution Time of Linear Buckling Finite Element Analyses, M.Sc. Thesis, Aalborg University, Department of Mechanical and Manufacturing Engineering, 2012.

c.Rekha M. B., Kalurkar L. G, Study of Buckling Behavior of Beam and Column, IOSR Journal of Mechanical and Civil Engineering, p.p. 36-40,Vol. 11, No. 4, 2014.

d.Hussein, H. A., Buckling of square columns under cycling loads for nitriding steel DIN (ck45, ck67, ck101), Ph.D. Thesis, University of Technology, Mechanical Engineering Department, March 2010.

e.Amir J, Zodiac A, Buckling of Beams and Columns under Combined Axial and Horizontal Loading with Various Axial Loading Application Locations, Journal of Theoretical and Applied Mechanics, Sofia, pp19 - 30, Vol.42, No.4, 2012. 
f.Yuan.H.X., Wang.Y.Q, T.Chang, X.X.Du, Y.D. Bu, Y.D. Bu, Y.J.Shi, Local buckling and post-buckling strength of extruded aluminum alloy stub columns with slender I-section" Thinwalled structures pp140-149, Vol. 90, 2015.

g.Mei L, Lulu Z, Peijun W, YicunC, Buckling behaviors of모section aluminum alloy columns under axial compression, Engineering Structures, , pp 127-137, Vol 95 ,2015.

h.Mei L, Peijun W, YicunC., Experimental investigation on local buckling behaviors of stiffened closed-section thin-walled aluminum alloy columns under compression, Thin-Walled Structures pp188-198, Vol 94, 2015.

i.Gere.J. M., Mechanics of Material, 7th ED, Thomson LearningAcademic Resource Centre, Stanford University, 2009.

j.Hearn.E. J., Mechanics of materials, 3th ED, University of Warwick, United Kingdom, 1997.

k.Fadhel E. Z., Effect of Shot Peening on The Buckling Behaviour of Steel CK35 under Combined Loading, Ph.D. Thesis, University of Technology, Mechanical Engineering Department, April 2014.

1.Metals Handbook, Vol.2 - Properties and Selection: Nonferrous Alloys and Special-Purpose Materials, ASM International, $10^{\text {th }} \mathrm{ED}, 1990$. 